\title{
Fostering Visitors' Pro-environmental Behaviour in an Urban Park
}

Recognizing the increasing importance of sustainable environment, this research explored visitors' pro-environmental decision-making process in an urban park context. This study investigated the relationships among attitudes, subjective norms, perceived behaviour control, positive and negative anticipated emotions as well as behavioural intentions. The results suggest that positive anticipated affects positively influenced low effort and high effort pro-environmental behavioural intentions. In addition, positive anticipated affects mediated the relationship between cognitive factors and behavioural intentions. Interestingly negative anticipated affects did not influence behavioural intentions. Further analysis revealed subjective norm was the strongest predictor of intentions, especially the low effort pro-environmental behavioural intentions. The research advances the conceptual understanding of the role of each construct in generating park visitors' intentions to perform environmentally responsible behaviours while visiting an urban park.

Keywords: Pro-environmental behaviour; Intentions; Positive anticipated affect; Negative anticipated affect; Urban parks; Theory of Planned Behaviour; Ecotourism; Park visitors; Subjective norms; China 


\section{Introduction}

Urban parks contribute to physical and mental health, in addition to the preservation of biodiversity (Weiler, Moore, \& Moyle, 2013). Parks in urban locations are also critical for public recreation, providing outdoor activities that foster socialization, connectivity and community engagement (Wei, 2017). However, an increasing number of visitors, coupled with both conscious and unconscious behaviours, have been identified to place additional pressure on the management of the environment in urban parks (Pickering, 2010). To minimize human impacts on the natural environment, scholars have sought to encourage pro-environmental behaviour (Bamberg \& Moser, 2007; Chiu, Lee, \& Chen, 2014; Steg, Bolderdijk, Keizer, \& Perlaviciute, 2014), which refers to the behaviour minimizing damage to the environment or in some cases even benefit the environment (Cottrell, 2003; Steg \& Vlek, 2009).

The Theory of Planned Behaviour (TPB) has been applied to study a variety of pro-environmental behaviours, such as recycling at school (De Leeuw, Valois, Ajzen, \& Schmidt, 2015), selecting green hotel (Han \& Kim, 2010), using public transportation (Bamberg, Hunecke, \& Blöbaum, 2007) and purchasing green products (Chan \& Lau, 2002). As suggested by Kals, Schumacher, and Montada (1999), ecological behaviour cannot be viewed as a mere result of cognitive process. The behaviour-related processes comprise affective responses, such as the anticipated emotions (Perugini \& Conner, 2000). According to Onwezen, Bartels, \& Antonides (2014b) and Harth, Leach, and Kessler (2013), both positive and negative anticipated emotions are explicitly relevant to pro-environmental behaviour. Anticipated emotions have also been empirically identified as important 
contributors to guiding environmental decisions or pro-social behaviours (Conner, Godin, Sheeran, \& Germain, 2013; Han \& Hyun, 2017; Kim, Njite, \& Hancer, 2013).

A key rationale behind the integration of new constructs (e.g. anticipated emotions) into TPB is to provide much needed conceptual clarification on the theoretical mechanisms which underpin PEB to better understand individuals' decision-making process (Chan \& Lau, 2001; Lee, Song, Bendle, Kim, \& Han, 2012; Onwezen, Antonides, \& Bartels, 2013). Nevertheless, in tourism, the effect of anticipated emotions has received relatively less attention than that of cognitive factors in TPB theoretical framework (Curtis, Ham, \& Weiler, 2010). In particular, limited studies have critically examined the relationship between anticipated affective variables and pro-environmental behaviour in an urban park setting.

As suggested by Ramkissoon, Weiler, \& Smith (2012), encouraging visitors' pro-environmental behavioural practice may contribute to the improvement of the environment in parks and thus benefit the future generations. Generating a better understanding of visitors' behaviours helps to more effectively realizing management objectives in natural settings, such as cost savings on litter collection and fewer detrimental impacts on wildlife (Brown, Ham, \& Hughes, 2010). Recognizing these benefits, park authorities are increasingly interested in peoples' decision-making process to promote the sustainability of natural resources and environment (Halpenny, 2010). A better understanding of pro-environmental decision-making process, how it arises, how it is perceived by visitors, is therefore necessary to encouraging pro-environmental behaviour and promoting environment sustainability of urban parks.

This study aims to integrate affective drivers into TPB model to understand visitor's 
pro-environmental behaviour in an urban park setting. Specifically, this research assessed the comparative importance of five variables (i.e., positive and negative anticipated emotions, attitudes, subjective norms, and perceived behaviour control) in generating pro-environmental decisions and tested the mediating role of affective processes.

\section{Pro-environmental Behaviour (PEB) in Parks}

"Pro-environmental behaviour" (Bamberg \& Moser, 2007) or "Environmentally supportive behaviours" (Huddart-Kennedy, Beckley, McFarlane, \& Nadeau, 2009) are used by researchers to describe behaviours that minimize ecological harm, advocate natural resource conservation and promote sustainability of the environment (Larson, Stedman, Cooper, \& Decker, 2015). This research adopts the term pro-environmental behaviour to refer to the behaviour that aims to reduce the damage to the environment or even promote the sustainability of environment (Cottrell, 2003; Steg \& Vlek, 2009).

Increasing visitation has been demonstrated in previous studies to lead to cumulative negative impacts, placing additional pressure on the environment of parks (Marion \& Reid, 2007; Ramkissoon, Smith, \& Weiler, 2013). This has lead researchers to explore mechanisms to promote pro-environmental behaviours in natural settings and protect natural resources (Lehman \& Geller, 2004). Ramkissoon et al. (2012), for instance, proposed a conceptual framework that comprises four sub-constructs of place attachment and critically examined the likely influence of place attachment on visitors' PEB in parks and PEB in daily life. They also empirically demonstrated that the place attachment has a positive influence on place satisfaction and pro-environmental intentions (Ramkissoon et al., 2013). 
Scholars suggested different types of PEB might be influenced by different variables, which subsequently has an impact on our understanding of individuals' PEB and environmental management (Lee, Jan, \& Huang, 2015; Lee, Jan, \& Yang, 2013). For example, Lee, Jan, and Huang (2015) conceptualized PEB as general and site-specific PEB to measure tourists' behavioural intentions while visiting intertidal zones. The results showed that general and site-specific PEB are respectively affected by different aspects of a recreation experience. Halpenny (2010) measured the two kinds of PEB (general and park-related) and found that place attachment is an important precursor to individuals' place-related pro-environmental intentions. Ramkissoon et al. (2013) classified PEB into low effort PEB and high effort PEB according to its easiness or the effort that park visitors need to make. The place satisfaction was found to positively influence low effort PEB but negatively influence high effort PEB (Ramkissoon et al., 2013).

The scope of behaviours associated with sustainable tourism is much larger (Landon, Woosnam, \& Boley, 2018). Given that, this study employed low effort and high effort PEB measures in Ramkissoon et al. (2013) and the items assessing PEB were revised in accordance with the study context. The low effort PEB refers to eco-friendly behaviours that requires less effort (e.g. picking up letter or learning about the environment of parks), whereas high effort PEB comparatively need more time and attention investment and other efforts (e.g. volunteering time to park-protecting projects). 


\section{The Theory of Planned Behaviour}

The Theory of Planned Behaviour is designed to account for human behaviours in specific settings (Ajzen, 1991). This theory assumes that an individual tends to perform a particular behaviour to the degree that he or she has a positive attitude toward the behaviour, perceives pressure to perform the behaviour from social environment, and expects to have control over performing the behaviour (Richard, Pligt, \& Vries, 1996). According to Ajzen (1991), attitude is the extent to which a person has either a favorable or unfavorable assessment of the behaviour in question; subjective norms refer to an individual's perception of the social pressure to perform or not to perform the specific behaviour; and perceived behavioural control refers to the perceived ease or difficulty of behaving. It is important to distinguish social norms from subjective norms, as the social norms involve a wide range of acceptable behaviours in a social group or society but these norms might not be fully absorbed by individuals. At this point, subjective norms indicate individuals' perceived norms which may or may not reflect what most important others think should be done (Fishbein \& Ajzen, 2011).

The effects of attitude, subjective norms and perceived behavioural control in predicting intention have been examined in previous studies, although the significance of each factor is incongruent in terms of different behaviours and situations (Teng, Wu, \& Liu, 2015). For example, in investigating visitors' willingness to pay for the conservation of parks, López-Mosquera and Sánchez (2012) found perceived behavioural control was the strongest determinant, while perceived social pressure was the next strongest determinant. Chen and Tung (2014) demonstrated that attitudes toward green hotels, subjective norms, and perceived 
behavioural control exerted a positive influence on consumers' intention to visit green hotels. In a study on non-compliance in national parks, Goh, Ritchie and Wang (2017) reported subjective norms and attitudes as the key antecedents of PEB. Similarly, Lee and Jan (2017) showed that environmental attitudes, subjective norms, perceived behavioural control have positive impacts on ecotourism behavior among nature-based tourists. Based on these notions, this study proposes that an increase in positive attitudes toward eco-friendly behaviours, perceived pressure to perform, and the control over performing the behaviours positively influence low effort and high effort pro-environmental intentions.

H1. Attitude positively influences low effort pro-environmental intention.

H2. Attitude positively influences high effort pro-environmental intention.

H3. Subjective norms positively influence low effort pro-environmental intention.

H4. Subjective norms positively influence high effort pro-environmental intention.

H5. Perceived behavioural control positively influences low effort pro-environmental intention.

H6. Perceived behavioural control positively influences high effort pro-environmental intention.

\section{Anticipated Affect and its Relationships with TPB Variables}

Existing studies also indicate that affective variables make an independent contribution to the formation of intentions to perform a PEB (Han, Hwang, \& Lee, 2017; Han \& Hyun, 2017; Hur \& Jang, 2015; Kim et al., 2013). The affect results from an evaluative perception of actual, imagined, or anticipated relationship between a person and the environment (Lazarus, 
1982). Rivis, Sheeran, and Armitage (2009) argue that anticipated feelings refer to the prospect of experiencing positive or negative affects along with performing or not performing a specific behaviour. Although affect is generally regarded as an umbrella concept that covers emotion and feeling (Bagozzi, Gopinath, \& Nyer, 1999; Cohen, Pham, \& Andrade, 2008), the anticipated affect, anticipated emotion, and anticipated feeling have been used interchangeably to refer to similar measurements of imagined emotional responses in the studies on PEB integrating affective factors (e.g. Han, 2014; Han \& Hur, 2016; Han \& Hyun, 2017).

Notably, the construct of attitudes in the TPB model also denote affective responses or feelings towards the attitude object (Ajzen, 2005), but the anticipated affect can be distinguished in two important ways. First, attitudes are evaluative in nature while the anticipated affective responses are emotional in nature. In this regard, attitudes are assessed by means of overall evaluation measures and anticipated affect tends to be assessed through emotion indicators (Fishbein \& Ajzen, 2011). Second, anticipated affect tends to examine not only the positive affect expected after performing certain behaviours, but also the negative affect associated with non-performance of those behaviours (Conner et al., 2013). In the present study, positive and negative anticipated affects are constituents of affective factors.

Kim et al. (2013) indicated that inducing more anticipated regret can increase consumers' intentions to select eco-friendly restaurants. In examining convention travellers' pro-environmental intentions, Han, Hwang and Lee (2017) empirically identified that anticipated emotions (i.e. anticipated guilt and pride) are important drivers of intention to practice green activities. Similar results can be found in a museum context, which showed 
positive and negative anticipated affects are contributors to increasing pro-environmental decisions (Han \& Hyun, 2017). However, to date, applications of anticipated affects in investigating PEB in urban park settings are scarce. Given these, the present study hypothesizes that anticipated affects positively influence low effort and high effort pro-environmental intentions.

H7. Positive anticipated affect positively influences low effort pro-environmental intention.

H8. Positive anticipated affect positively influences high effort pro-environmental intention.

H9. Negative anticipated affect positively influences low effort pro-environmental intention.

H10. Negative anticipated affect positively influences high effort pro-environmental intention.

Additionally, scholars seek to integrate anticipated affects into existing theoretical frameworks such as TPB (De Leeuw et al., 2015). Onwezen, Bartels, \& Antonides (2014a) found that anticipated emotions (i.e., guilt and pride) play a mediating role between attitude, descriptive norms and intentions to buy organic products across individualistic and collectivistic countries. Moreover, it has been revealed that when anticipated emotions were added into TPB, attitudes and subjective norms contribute to activating an individual's anticipated emotions (Hynie, MacDonald, \& Marques, 2006; Onwezen et al., 2014a, 2014b). It is also suggested that cognitive evaluations have great power to shed light on emotional responses (Breitsohl \& Garrod, 2016; Lazarus, 1991). The effects of attitudes, subjective norms and perceived behavioural control on anticipated affect in TPB model in nature-based settings have been unexplored and require conceptual clarification and theoretical refinement. 
Therefore, the following hypotheses were developed:

H11. Attitude positively influences positive anticipated affect.

H12. Subjective norms positively influence positive anticipated affect.

H13. Perceived behavioural control positively influences positive anticipated affect.

H14. Attitude positively influences negative anticipated affect.

H15. Subjective norms positively influence negative anticipated affect.

H16. Perceived behavioural control positively influences negative anticipated affect.

Based on the assertions of previous studies, we proposed 16 research hypotheses and the basic conceptual model is illustrated in Figure 1.

FIGURE 1 NEAR HERE

\section{Methodology}

\section{Measurement Instruments}

The questionnaire included seven parts (please refer to Supplementary data). A Seven-point Likert-type scale from "Strongly disagree" (1) to "Strongly agree" (7) was applied to all latent variables. Demographic variables, i.e., age, gender, occupation, education and income, were also included in the instrument. The questionnaire was reviewed by academics, practitioners, and park visitors (63 tourists at the park) for face validity. The outcome of this process was minor adjustments to the wording, phrasing and formatting.

The attitude, subjective norms and perceived behavioural control were measured with three items respectively and were adopted from Ajzen (1991) and Han (2015). One item in attitude measures (i.e. For me, behaving eco-friendly at park is Good) in Han (2015) was omitted as it 
had almost the same meaning in Chinese as another item (i.e. For me, behaving eco-friendly at park is Beneficial). Positive anticipated affect and negative anticipated affect were employed from Onwezen et al. (2013) and Han and Hyun (2017). The positive anticipated affect was evaluated with four items (i.e. If I practice environmentally responsible actions at park that minimizes its negative impact on the environment, I would feel [1] proud, [2] accomplished, [3] confident and [4] worthwhile). However, due to low factor loadings, the third item was deleted from final analysis. The negative anticipated affect was evaluated with three items (i.e. If I fail to practice environmentally responsible actions at park that minimizes its negative impact on the environment, I would feel [1] guilty, [2] remorseful and [3] bad). Low effort and high effort pro-environmental behavioural intention items were operationalized by three items respectively. They were adapted from Ramkissoon et al. (2013) and modified in accordance with the demands of the study context (e.g. I am willing to learn more about the state of the park environment; I am willing to talk to site managers about the environmental issues at this park.).

\section{Data Collection and Sample Profile}

The focus of this research is Beijing Olympic Forest Park of China (BOFP), covering an area of approximately 680 square hectometers (Huo et al., 2014). As an area for tourism and recreation BOFP has easy access locating along the Beijing Subway and requires no admission fee. BOFP is also a wildlife protection area, with abundant ecological resources, fine infrastructure and entertainment facilities and is extremely popular among locals and tourists from different parts of China.

Data was collected in November and December of 2016. The convenience sampling 
method was adopted to identify the respondents. At the exit of the park, the first participant was chosen by trained university students investigators, and following that, every fifth person passing in front of the investigator was approached and asked to complete the questionnaires on a voluntary basis (Balomenou \& Garrod, 2014). The questionnaire was distributed and returned on-site in order to increase the response rate. In total, 300 park visitors were surveyed and 290 questionnaires were returned. After excluding the unusable cases with incomplete responses, we used 257 completed responses for data analysis. The sample size is acceptable for the latent variable model in this study where the estimation method is maximum likelihood and where all outcomes are continuous and normally distributed (Kline, 2015). According to the $N: q$ rule in Jackson (2003), the ratio of the number of cases $(\mathrm{N})$ in our research to the number of model parameters $(\mathrm{q})$ is about 16:1, which is far above the less ideal ration (10:1) and near the recommended sample-size-to-parameters ration (20:1).

Furthermore, there is a need to examine the common method bias (CMB) in this study, as the variable measurements were collected using the same manner from the same participants (Podsakoff \& Organ, 1986). The present study applied two measures to identify and safeguard against common method variance. First, the Harman's single-factor test was performed by loading all of the self-reported items into an exploratory factor analysis. A total of six factors appeared in EFA results and each of them explained less than $34 \%$ of the total variance between the variables. When one factor has less than $50 \%$ of the variance from the variables, it means there is no serious CMB (Podsakoff, MacKenzie, \& Lee, 2003). Also, when the common method variance appears, a confirmatory factor analysis involving all the constructs should generate a single method factor (Podsakoff \& Organ, 1986). The results 
revealed a significantly worse fit of the single-factor model with IFI, CFI, and TLI values lower than 0.9 and RMSEA higher than 0.2. Accordingly, the common method variance did not significantly influence the study results based on the evidence from two statistical tests.

Of the 257 respondents, 115 participants were males (45\%) and 142 participants were females (55\%). In particular, about 48.2\% indicated that they earned a bachelor's degree; $45.9 \%$ earned a graduate degree (Table 1). Sample demographics are not very balanced in terms of gender and are characterized by predominantly younger and well-educated target group. Therefore, care should be taken in the interpretation of the results due to sampling characteristics.

\section{TABLE 1 NEAR HERE}

\section{Data Analysis}

SPSS version 18.0 and AMOS version 21.0 were used for correlation, factor analyses and Structural Equation Modeling (SEM). Structural Equation Modeling has been widely suggested to be the most appropriate technique for complex model testing (Kiatkawsin \& Han, 2017; Nunkoo, Ramkissoon, \& Gursoy, 2013). As suggested by Anderson and Gerbing (1988), a measurement model using Confirmatory Factor Analysis (CFA) was evaluated at the first step (Table $2 \& 3$ ). Indicators of each construct were all acceptable indicating that constructs have a unidimensional measurement scale (Sethi \& King, 1994). Results showed that the model includes an appropriate fit to the data $\left(\chi^{2} / \mathrm{df}=1.752, \mathrm{RMSEA}=.054, \mathrm{CFI}=.962\right.$, $\mathrm{IFI}=.962, \mathrm{NFI}=.916)$.

All the standardized loadings for the indicators of each construct were higher than .50 , and all factor loadings were significant at $p<.001$. Composite reliability was calculated using 
standardized factor loadings and indicator error variances for each variable. Values of composite reliability for every construct fell between .680 and .927 , which were greater than Bagozzi and Yi's (1988) suggested cutoff of .600. That is, the measurement items for each study variable are internally consistent. Subsequently, average variance extracted (AVE) values were computed. AVE values fell between .519 and .810 which is more than Fornell and Larcker's (1981) suggested threshold of .500. In addition, AVE values were higher than the squared correlation between variables. The results indicated the convergent and discriminant validity of the measurement model have been established (Fornell \& Larcker, 1981).

\section{TABLE 2 \& 3 NEAR HERE}

A structural equation model comprising all research variables was constructed. Table 4 and Figure 2 present the summary of the results. An examination of the goodness-of-fit statistics revealed that the final model fit to the collected data well $\left(\chi^{2}=312.586, \mathrm{df}=213, \mathrm{p}<.001\right.$, $\left.\chi^{2} / \mathrm{df}=1.468, \mathrm{RMSEA}=.043, \mathrm{CFI}=.976, \mathrm{IFI}=.976, \mathrm{TLI}=.971\right)($ Byrne, 2001).

\section{FIGURE 2 NEAR HERE}

\section{TABLE 4 NEAR HERE}

Subjective norms exerted a positive and significant influence on visitors' low effort and high effort PEB $(\beta=.429, \rho<.001 ; \beta=.181, \rho<.05)$, supporting Hypotheses 3 and 4. Yet, attitude and perceived behavioural control did not directly affect pro-environmental intention in this sample, rejecting Hypotheses 1, 2, 5 and 6. Regarding the endogenous variable, positive anticipated affect play a critical role in increasing both low effort and high effort PEB $(\beta=.308, \rho<.001 ; \beta=.318, \rho<.001)$, supporting Hypotheses 7 and 8 . 
Yet, the impact of negative anticipated affect was not significant, rejecting Hypotheses 9 and 10. The hypothesized associations among cognitive factors and anticipated emotions were tested (H11-H16).

Results demonstrated that the impacts of attitude $(\beta=.424, \rho<.001)$, subjective norms $(\beta=.143, \rho<.05)$ and perceived behavioural control $(\beta=.382, \rho<.001)$ on positive anticipated affect were significant and positive. These results supported Hypotheses 11, 12 and 13. The relationships between cognitive variable and negative anticipated affect were assessed. As expected, attitude $(\beta=.289, \rho<.001)$, subjective norms $(\beta=.266, \rho<$ $.01)$ and perceived behavioural control $(\beta=.238, \rho<.05)$ exerted a significant and positive influence on negative anticipated affect, thus supporting Hypotheses 14, 15 and 16.

The indirect impacts of constructs were also examined by performing a bootstrap analysis, which provides a relatively straightforward manner to identify the significance of indirect effects (Han \& Hyun, 2017). Results indicated that attitude, subjective norms and perceived behavioural control have a significant indirect impact on the endogenous variables through positive anticipated affect: on low effort PEB $(\beta=.149, \rho<.01 ; \beta=.045, \rho<.05 ; \beta$ $=.117, \rho<.01)$ and on high effort PEB $(\beta=.177, \rho<.01 ; \beta=.054, \rho<.05 ; \beta=$ $.140, \rho<.01)($ Table 5). These findings suggested that positive anticipated affect plays a significant mediating role in the proposed conceptual framework. Overall, positive anticipated affect fully mediates attitudes, perceived behavioural control and PEB but partially mediates subjective norms and PEB.

As for the total influence on low effort PEB, subjective norms was the greatest among research variables $(\beta=.488, \rho<.05)$, followed by positive anticipated affect $(\beta=.308$, 
$\rho<.001)$, attitude $(\beta=.149, \rho<.01)$, and perceived behavioural control $(\beta=.117, \rho$ $<.01)$. For the total impact on high effort PEB, positive anticipated affect was the greatest among research variables $(\beta=.318, \rho<.001)$, followed by subjective norms $(\beta=.269$, $\rho<.05)$, attitude $(\beta=.177, \rho<.01)$, and perceived behavioural control $(\beta=.140, \rho$ $<.01)$.

\section{TABLE 5 NEAR HERE}

\section{Discussion}

The study advances the conceptual understanding of the role of each construct in TPB model and anticipated affects in generating visitors' intentions to perform environmentally responsible behaviours in an urban park, which has as of yet hardly been explored in the existing park literature. The research indicated that positive anticipated affect positively influenced both low effort and high effort PEB. It is also identified that the impact of attitude, subjective norms, and perceived behavioural control on park visitors' intention were asymmetric. This study thus delivers meaningful implications to park practitioners. In particular, positive anticipated affect and subjective norms should be the priority for the design of urban park interpretation and environment education activity in collective culture to maximize individuals' pro-environmental intentions.

\section{Theoretical Implications}

The study revealed different impact levels of positive and negative anticipated affects on pro-environmental behaviours. Park visitors' positive anticipated affect plays a significant and direct role in intentions to perform pro-environmental behaviours. The total impact of positive anticipated affect on low effort PEB was not significantly different from the total 
impact on high effort PEB. This echoes the findings of previous studies that positive anticipated affect strongly affected pro-environmental behavioural intentions (Han \& Hyun, 2017; Onwezen et al., 2013; Onwezen et al., 2014a, 2014b). The result suggests that as the level of positive anticipated affect increased, park visitors had more pro-environmental behavioural intentions. As indicated in previous literature, this may be because individuals are strongly motivated to seek out positive feelings, which often guide intentions to engage in pro-environmental behaviour (Baumeister, Vohs, DeWall, \& Zhang, 2007; Han \& Hyun, 2017; Onwezen et al, 2014a).

Interestingly, negative anticipated affect did not regulate pro-environmental behavioural intentions in this sample. The result is inconsistent with Han and Hyun (2017), Onwezen et al. (2014a), and Onwezen et al. (2013)'s assertions that negative anticipated emotional process guides pro-environmental decision-making. Nevertheless, Lazarus (1991) indicated that coping with negative emotions might either by deploying attention or by altering the meaning of the person-environment relationship. In this study setting, park visitors might choose to cope with negative feelings by attention deployment (e.g. avoidance) or by denial or distancing, in which the distressing emotion associated with harm or threat on the environment is made moot. Therefore, it is not surprising that negative anticipated affect did not directly impact pro-environmental behavioural intentions in this study.

Another key contribution of this research is identifying the mediating role of positive anticipated affect. In other words, cognitive responses (i.e. attitude, subjective norms and perceived behavioural control) influence PEB through the anticipated affective factors, especially the positive anticipated affect. In addition, cognitive factors exert a significant and 
positive influence on both positive and negative anticipated affects. This result supported Onwezen et al. (2014a) and Hynie et al.'s (2006) indication that attitudes and subjective norms play an important role in the formation of anticipated emotional outcomes. It is also consistent with the essence of appraisal theory that emotions are triggered by cognitive evaluations of situations and events (Roseman \& Smith, 2001).

Meanwhile, the study contributed to the literature by identifying the different impact of each cognitive variable on behavioural intention within urban park settings. Subjective norms had a direct and greatest influence on low effort and high effort PEB, which is consistent with earlier findings from the study by Borges and Lansink (2016). They emphasized the role of the collective culture in accounting for the higher impact of subjective norms in increasing farmers' intentions to use improved natural grassland. The effect of subjective norm in the present study reveals the decisive role of perceived social pressure of important persons, family or friends on park visitors' PEB, especially low effort PEB (i.e. recycling, learning, persuading). This result connects to the sample from China, where a collective culture remains relatively dominant in many aspects of daily life.

Attitude had an insignificant direct impact and marginal total effect on park visitors' PEB. Due to the potential of social desirability bias (Fisher, 1993) the insignificant relationship between attitude and behavioural intention might be connected to respondent's tendencies to respond in a socially desirable way, which is probably inconsistent with some visitors' real behavioural intentions at the park. For example, visitors tended to agree that behaving eco-friendly (e.g. not feeding animals with bread) in park was beneficial, but felt that if they did not feed animals, others would probably feed them anyway. This phenomenon was 
described as "denial of responsibility" in Juvan and Dolnicar (2014)'s study, which was believed to be a contributor to attitude-behaviour gap. This research also found that perceived behavioural control in an urban park did not predict behavioural intentions. According to Carrus, Passafaro, and Bonnes (2008), a person might feel that an individual's intention to recycle is because of the willingness to contribute to environmental conservation, without considering whether such an action is under their control or not (i.e., perceived behavioural control).

\section{Managerial Implications}

In addition to the theoretical implications arising from this research, this study provides significant managerial implications for park management and practice. Notably, caution should be taken when applying the findings into practice, as the sample of this study are comparatively younger. The findings revealed that in an urban park context an increase in positive anticipated feelings was positively related to park visitors' environmentally responsible intentions. Considering park visitors' positive anticipated affect in environment education and interpretation therefore should be the priority for site managers to maximize individuals' pro-environmental intentions.

Specifically, park managers should strive to encourage visitors' positive attitudes and enhance their perceived behavioural control in order to induce their positive anticipated affect. These may involve making necessary pro-environmental resources and opportunities available to visitors and communicating the benefits and significance of eco-friendly behaviours to visitors through the on-site interpretation system and the relevant social media. On the other hand, the findings showed that visitors' negative feelings did not trigger PEB in 
this research. Park visitors might choose to cope with negative feelings by attention deployment (e.g. avoidance) or by denial, in which the distressing emotion associated with harm or threat on the environment is made moot. Therefore, considering park visitors' negative anticipated affect should not be the priority for site managers to maximize individuals' pro-environmental intentions in this study setting.

The significant effect of subjective norms indicates that in order to increase visitors' PEB intentions, especially low effort intention, it could be effective for practitioners to increase perceived social pressure on park visitors. That is, park managers should always remind themselves of the power of opinion leadership in disseminating pro-environmental messages in a Chinese cultural setting (Chan \& Lau, 2002). For example, Pro-environmental campaigns in parks led by the mayors, community officials or celebrities are likely to generate awareness and engagement towards sustainable behaviours. In addition, if park visitors' friends, family members and community gain more knowledge about sustainability of environment and support pro-environmental practices, then they might share the relevant knowledge or beliefs with park visitors, which could be a powerful force in favour of promoting eco-friendly behaviours by visitors. It is also worth noticing that subjective norms exert more influence on low effort behavioural intention than on high effort behavioural intention. Therefore, using subjective norms to encourage recycling, learning, and persuasion might be more effective than to encourage high effort PEB.

\section{Limitations and future research}

Inevitably, this study has several limitations, many of which were mitigated, however some need to be addressed in future research. First, this research is limited by its focus on one 
urban park in China. As such, future studies should be replicated in conceptually related contexts. Another limitation of this study concerns the use of pro-environmental intention instead of real behaviour in the model. An ideal approach for future studies would be to investigate actual behaviour (e.g., using CCTV monitoring, GPS tracking etc.), which increases the external validity of the results. Third, the participants in the on-site surveys were younger and hence more representative sample should be investigated in future replications and extensions. Finally, future studies need to consider the impact of contextual factors or outside environment in addition to cognitive and affective factors. This analysis could help industry experts to better develop strategies and customize interventions even further, and therefore increase the efficacy of pro-environmental behaviour in an urban park setting. 


\section{References}

Ajzen, I. (1985). From intentions to actions: a theory of planned behavior. In J. Kuhl, \& J. Beskmann (Eds.), Action control: From cognition to behavior (pp. 369-391). New York, NY: Springer.

Ajzen, I. (1991). The theory of planned behavior. Organizational Behavior and Human Decision Processes, 50, 179-211.

Ajzen, I. (2005) Attitudes, Personality and Behavior (2nd ed.). Milton-Keynes, England: Open University Press.

Anderson, J. C., \& Gerbing, D. W. (1988). Structural equation modeling in practice: A review and recommended two-step approach. Psychology Bulletin, 103, 411-423.

Bagozzi, R. P., Gopinath, M., \& Nyer, P. U. (1999). The role of emotions in marketing. Journal of the Academy of Marketing Science, 27, 184-206.

Bagozzi, R. P., \& Yi, Y. (1988). On the evaluation of structural equation models. Journal of the Academy of Marketing Science, 16, 74-94.

Balomenou, N., \& Garrod, B. (2014). Using volunteer-employed photography to inform tourism planning decisions: A study of St David's Peninsula, Wales. Tourism Management, 44, 126-139.

Bamberg, S., Hunecke, M., \& Blöbaum, A. (2007). Social context, personal norms and the use of public transportation: Two field studies. Journal of Environmental Psychology, 27(3), 190-203.

Bamberg, S., \& Moser, G. (2007). Twenty years after Hines, Hungerford, and Tomera: A new meta-analysis of psycho-social determinants of pro-environmental behaviour. Journal of Environmental Psychology, 27, 14-25.

Baumeister, R. F., Vohs, K. D., DeWall, C. N., \& Zhang, L. (2007). How emotion shapes behavior: feedback, anticipation, and reflection, rather than direct causation. Personality and Social Psychology Review, 11, 167-203.

Borges, J. A. R., \& Lansink, A. G. O. (2016). Identifying psychological factors that determine cattle farmers' intention to use improved natural grassland. Journal of Environmental Psychology, 45, 89-96.

Brown, T. J., Ham, S. H., \& Hughes, M. (2010). Picking up litter: An application of theory-based communication to influence tourist behaviour in protected areas. Journal of Sustainable Tourism, 18, 879-900.

Byrne, B. M. (2001). Structural equation modeling with AMOS: Basic concepts, applications, and programming. Hillsdale, NJ: Erlbaum. 
Carrus, G., Passafaro, P., \& Bonnes, M. (2008). Emotions, habits and rational choices in ecological behaviours: The case of recycling and use of public transportation. Journal of Environmental Psychology, 28, 51-62.

Chan, L., \& Bishop, B. (2013). A moral basis for recycling: Extending the theory of planned behaviour. Journal of Environmental Psychology, 36, 96-102.

Chan, R. Y., \& Lau, L. B. (2002). Explaining green purchasing behavior: A cross-cultural study on American and Chinese consumers. Journal of international consumer marketing, 14(2-3), 9-40.

Chen, C. F., \& Chen, F. S. (2010). Experience quality, perceived value, satisfaction and behavioural intentions for heritage tourists. Tourism Management, 31, 29-35.

Chen, M. F., \& Tung, P. J. (2014). Developing an extended theory of planned behavior model to predict consumers' intention to visit green hotels. International journal of hospitality management, 36, 221-230.

Cheng, T. M., \& Wu, H. C. (2014). How do environmental knowledge, environmental sensitivity, and place attachment affect environmentally responsible behavior? An integrated approach for sustainable island tourism. Journal of Sustainable Tourism, 23, 557-576.

Chiu, Y. T. H., Lee, W. I., \& Chen, T. H. (2014). Environmentally responsible behavior in ecotourism: Antecedents and implications. Tourism Management, 40, 321-329.

Cohen, J. B., Pham, M. T., \& Andrade, E. B. (2008). The nature and role of affect in consumer behavior. In C. P. Haugtvedt, P. M. Herr, \& F. R. Kardes (Eds.), Handbook of consumer psychology (pp. 297-348). New York, NY: Taylor \& Francis.

Conner, M., Godin, G., Sheeran, P., \& Germain, M. (2013). Some feelings are more important: Cognitive attitudes, affective attitudes, anticipated affect, and blood donation. Health Psychology, 32, 264-272.

Cottrell, S. P. (2003). Influence of socio-demographics and environmental attitudes on general responsible environmental behavior among recreational boaters. Environment and Behavior, 35, 347-375.

De Leeuw, A., Valois, P., Ajzen, I., \& Schmidt, P. (2015). Using the theory of planned behavior to identify key beliefs underlying pro-environmental behavior in high-school students: Implications for educational interventions. Journal of Environmental Psychology, 42, 128-138.

Fishbein, M., \& Ajzen, I. (2011). Predicting and changing behavior: The reasoned action approach. New York, NY: Taylor \& Francis. 
Fisher, R. J. (1993). Social desirability bias and the validity of indirect questioning. Journal of Consumer Research, 20, 303-315.

Fornell, C., \& Larcker, D. F. (1981). Evaluating structural equation models with unobservable variables and measurement error. Journal of Marketing Research, 18, 39-50.

Goh, E., Ritchie, B., \& Wang, J. (2017). Non-compliance in national parks: An extension of the theory of planned behaviour model with pro-environmental values. Tourism Management, 59, 123-127.

Halpenny, E., A. (2010). Pro-environmental behaviours and park visitors: The effect of place attachment. Journal of Environmental Psychology, 30, 409-421.

Han, H. (2015). Travelers' pro-environmental behavior in a green lodging context: Converging value-belief-norm theory and the theory of planned behavior. Tourism Management, 47, 164-177.

Han, H., Hwang, J., \& Lee, S. (2017). Cognitive, affective, normative, and moral triggers of sustainable intentions among convention-goers. Journal of Environmental Psychology, 51, 1-13.

Han, H., \& Hyun, S. S. (2017). Fostering customers' pro-environmental behavior at a museum. Journal of Sustainable Tourism, 25(9), 1240-1256.

Han, H., \& Kim, Y. (2010). An investigation of green hotel customers' decision formation: Developing an extended model of the theory of planned behavior. International Journal of Hospitality Management, 29(4), 659-668.

Harth, N. S., Leach, C. W., \& Kessler, T. (2013). Guilt, anger, and pride about in-group environmental behaviour: Different emotions predict distinct intentions. Journal of Environmental Psychology, 34, 18-26.

Huddart-Kennedy, E., Beckley, T. M., McFarlane, B. L., \& Nadeau, S. (2009). Rural-urban differences in environmental concern in Canada. Rural Sociology, 74, 1-21.

Huo, S., Yu, H., Xi, B., Zan, F., Zhu, C., \& Zhang, J. (2014). Characteristics of dissolved organic nitrogen (DON) in the surface water of Beijing Olympic Forest Park. Environmental Earth Sciences, 71(9), 4021-4028.

Hynie, M., MacDonald, T. K., \& Marques, S. (2006). Self-conscious emotions and self-regulation in the promotion of condom use. Personality and Social Psychology Bulletin, 32, 1072-1084.

Jackson, D. L. (2003). Revisiting sample size and number of parameter estimates: Some support for the N:q hypothesis. Structural Equation Modeling, 10, 128-141.

Juvan, E., \& Dolnicar, S. (2014). The attitude-behaviour gap in sustainable tourism. Annals of 
Tourism Research, 48, 76-95.

Kals, E., Schumacher, D., \& Montada, L. (1999). Emotional affinity toward nature as a motivational basis to protect nature. Environment and behavior, 31, 178-202.

Kiatkawsin, K., \& Han, H. (2017). Young travelers' intention to behave pro-environmentally: Merging the value-belief-norm theory and the expectancy theory. Tourism Management, 59, 76-88.

Kim, Y. J., Njite, D., \& Hancer, M. (2013). Anticipated emotion in consumers' intentions to select eco-friendly restaurants: Augmenting the theory of planned behavior. International Journal of Hospitality Management, 34, 255-262.

Kline, R. B. (2015). Principles and practice of structural equation modeling. New York, NY: Guilford publications.

Kormos, C., \& Gifford, R. (2014). The validity of self-report measures of pro-environmental behaviour: A meta-analytic review. Journal of Environmental Psychology, 40, 359-371.

Landon, A. C., Woosnam, K. M., \& Boley, B. B. (2018). Modeling the psychological antecedents to tourists' pro-sustainable behaviors: an application of the value-belief-norm model. Journal of Sustainable Tourism, 1-16.

Larson, L. R., Stedman, R. C., Cooper, C. B., \& Decker, D. J. (2015). Understanding the multi-dimensional structure of pro-environmental behavior. Journal of Environmental Psychology, 43, 112-124.

Lazarus, R. S. (1982). Thoughts on the relations between emotion and cognition. American Psychologist, 37, 1019-1024.

Lazarus, R. S. (1991). Emotion and adaptation. New York, NY: Oxford University Press.

Lee, T. H., \& Jan, F. H. (2017). Ecotourism behavior of nature-based tourists: An integrative framework. Journal of Travel Research, 1-19.

Lee, T. H., Jan, F. H., \& Huang, G. W. (2015). The influence of recreation experiences on environmentally responsible behavior: The case of Liuqiu Island, Taiwan. Journal of Sustainable Tourism, 23, 947-967.

Lee, T. H., Jan, F. H., \& Yang, C. C. (2013). Conceptualizing and measuring environmentally responsible behaviors from the perspective of community-based tourists. Tourism Management, 36, 454-468.

Lehman, P. K., \& Geller, E. S. (2004). Behavior analysis and environmental protection: Accomplishments and potential for more. Behavior and Social Issues, 13, 13-32.

López-Mosquera, N., \& Sánchez, M. (2012). Theory of Planned Behavior and the Value-Belief-Norm Theory explaining willingness to pay for a suburban park. Journal 
of Environmental Management, 113, 251-262.

Marion, J. L., \& Reid, S. E. (2007). Minimising visitor impacts to protected areas: The efficacy of low impact education programmes. Journal of Sustainable Tourism, 15, $5-27$.

Nunkoo, R., Ramkissoon, H., \& Gursoy, D. (2013). Use of structural equation modeling in tourism research: Past, present, and future. Journal of Travel Research, 52(6), 759-771.

Onwezen, M. C., Antonides, G., \& Bartels, J. (2013). The Norm Activation Model: An exploration of the functions of anticipated pride and guilt in pro-environmental behaviour. Journal of Economic Psychology, 39, 141-153.

Onwezen, M. C., Bartels, J., \& Antonides, G. (2014a). Environmentally friendly consumer choices: Cultural differences in the self-regulatory function of anticipated pride and guilt. Journal of Environmental Psychology, 40, 239-248.

Onwezen, M. C., Bartels, J., \& Antonides, G. (2014b). The self-regulatory function of anticipated pride and guilt in a sustainable and healthy consumption context. European Journal of Social Psychology, 44, 53-68.

Perugini, M., \& Conner, M. (2000). Predicting and understanding behavioral volitions: The interplay between goals and behaviors. European Journal of Social Psychology, 30, 705-731.

Pickering, C. M. (2010). Ten factors that affect the severity of environmental impacts of visitors in protected areas. AMBIO: A Journal of the Human Environment, 39, 70-77.

Podsakoff, P. M., \& Organ, D. W. (1986). Self-reports in organizational research: Problems and prospects. Journal of Management, 12, 531-544.

Podsakoff, P. M., MacKenzie, S. B., \& Lee, J. Y. (2003). Common method biases in behavioral research: A critical review of the literature and recommended remedies. Journal of Applied Psychology, 88, 879-903.

Ramkissoon, H., Smith, L. D. G., \& Weiler, B. (2013). Testing the dimensionality of place attachment and its relationships with place satisfaction and pro-environmental behaviours: A structural equation modelling approach. Tourism Management, 36, 552-566.

Ramkissoon, H., Weiler, B., \& Smith, L. D. G. (2012). Place attachment and pro-environmental behaviour in national parks: The development of a conceptual framework. Journal of Sustainable Tourism, 20, 257-276.

Richard, R., Pligt, J., \& Vries, N. (1996). Anticipated affect and behavioral choice. Basic and Applied Social Psychology, 18, 111-129. 
Rivis, A., Sheeran, P., \& Armitage, C. J. (2009). Expanding the affective and normative components of the theory of planned behavior: A meta-analysis of anticipated affect and moral norms. Journal of Applied Social Psychology, 39, 2985-3019.

Roseman, I. J., \& Smith, C. A. (2001). Appraisal theory: Overview, assumptions, varieties, controversies. In T. Johnstone (Ed.), Appraisal processes in emotion: Theory, methods, research (pp. 3-19). New York, NY: Oxford University Press.

Russell, D. W., \& Russell, C. A. (2010). Experiential reciprocity: The role of direct experience in value perceptions. Journal of Travel \& Tourism Marketing, 27, 624-634.

Sethi, V., \& King, W. R. (1994). Development of measures to assess the extent to which an information technology application provides competitive advantage. Management Science, 40, 1601-1627.

Smith, C. A., \& Kirby, L. D. (2009). Putting appraisal in context: Toward a relational model of appraisal and emotion. Cognition and Emotion, 23, 1352-1372.

Steg, L., Bolderdijk, J. W., Keizer, K., \& Perlaviciute, G. (2014). An integrated framework for encouraging pro-environmental behaviour: The role of values, situational factors, and goals. Journal of Environmental Psychology, 38, 104-115.

Steg, L., \& Vlek, C. (2009). Encouraging pro-environmental behaviour: An integrative review and research agenda. Journal of Environmental Psychology, 29, 309-317.

Teng, Y. M., Wu, K. S., \& Liu, H. H. (2015). Integrating altruism and the theory of planned behavior to predict patronage intention of a green hotel. Journal of Hospitality \& Tourism Research, 39, 299-315.

Wei, F. (2017). Greener urbanization? Changing accessibility to parks in China. Landscape and Urban Planning, 157, 542-552.

Weiler, B., Moore, S. A., \& Moyle, B. D. (2013). Building and sustaining support for national parks in the 21st century: why and how to save the national park experience from extinction. Journal of Park and Recreation Administration, 31, 115-131. 
Table 1. Respondent profile

\begin{tabular}{lcc}
\hline Demographic traits & Distribution & Valid percentage (\%) \\
\hline Gender & & \\
Male & 115 & 45 \\
Female & 142 & 55 \\
Age & & \\
$\quad \leq 18$ & 2 & 46.3 \\
$19-30$ & 119 & 32.7 \\
$31-45$ & 84 & 14.4 \\
$46-60$ & 37 & 5.9 \\
$\geq 61$ & 15 & \\
Educational level & & 1.2 \\
Primary & 3 & 4.7 \\
High school & 12 & 48.2 \\
University or college & 124 & 45.9 \\
Postgraduate & 118 & \\
Monthly income (CNY) & & 26.8 \\
$\leq 2000$ & 69 & 18.7 \\
2001-4000 & 48 & 22.2 \\
4001-6000 & 57 & 15.6 \\
$6001-8000$ & 40 & 16.7 \\
$\geq 8000$ & 43 &
\end{tabular}


Table 2. Correlation, Mean, Standard Deviation, Average Variance Extracted and Composite Reliability

\begin{tabular}{|c|c|c|c|c|c|c|c|}
\hline & AT & SN & $\mathrm{PBC}$ & PAA & NAA & LEPBI & HEPBI \\
\hline AT & $.927^{\mathrm{a}}$ & & & & & & \\
\hline $\mathrm{SN}$ & $.574^{b}(.329)^{c}$ & .926 & & & & & \\
\hline PBC & $.584(.341)$ & $.643(.413)$ & .721 & & & & \\
\hline PAA & $.770(.593)$ & $.636(.404)$ & $.713(.508)$ & .889 & & & \\
\hline NAA & $.581(.338)$ & $.571(.326)$ & $.583(.340)$ & $.787(.619)$ & .910 & & \\
\hline LEPBI & $.519(.269)$ & $.634(.402)$ & $.488(.238)$ & $.577(.333)$ & $.459(.211)$ & .680 & \\
\hline HEPBI & $.415(.172)$ & $.392(.154)$ & $.388(.151)$ & $.420(.176)$ & $.350(.123)$ & $.691(.477)$ & .823 \\
\hline Mean & 6.429 & 6.174 & 5.485 & 6.253 & 6.309 & 6.669 & 4.908 \\
\hline SD & .793 & .905 & 1.058 & .906 & .899 & .603 & 1.184 \\
\hline AVE & .810 & .714 & .568 & .727 & .773 & .519 & .609 \\
\hline
\end{tabular}

Note. AT=Attitude; $S N=$ Subjective norms; $P B C=$ Perceived behavioural control; $P A A=$ Positive anticipated affects; NAA=Negative anticipated affects; $L E P B I=L o w$ effort pro-environmental behavioural intention; HEPBI =High effort pro-environmental behavioural intention.

Goodness-of-fit statistics: $\chi^{2} / d f=1.752, R M S E A=.054, C F I=.962, I F I=.962, N F I=.916$.

${ }^{a}$ Composite reliability, ${ }^{b}$ correlation, ${ }^{c}$ squared correlation. 
Table 3. Result of confirmatory factor analysis

\begin{tabular}{lll}
\hline Constructs & Items & Standardized factor loadings \\
\hline LEPBI & LEPBI1 & .675 \\
& LEPBI2 & $.521^{* * *}$ \\
HEPBI & LEPBI3 & $.728^{* * *}$ \\
& HEPBI1 & .783 \\
& HEPBI2 & $.748^{* * *}$ \\
PAA & HEPBI3 & $.808^{* * *}$ \\
& PAA1 & .828 \\
& PAA2 & $.864^{* * *}$ \\
NAA & PAA3 & $.862^{* * *}$ \\
& NAA1 & .764 \\
& NAA2 & $.934^{* * *}$ \\
AT & NAA3 & $.929 * * *$ \\
& AT1 & .877 \\
& AT2 & $.905^{* * *}$ \\
SN & AT3 & $.917 * * *$ \\
& SN1 & .864 \\
PBC & SN2 & $.965^{* * *}$ \\
& SN3 & $.818^{* * *}$ \\
& PBC1 & .773 \\
& PBC2 & $.554^{* * *}$ \\
\hline
\end{tabular}


Table 4. Coefficient, $t-v a l u e, R^{2}$ and hypotheses testing

\begin{tabular}{|c|c|c|c|c|c|c|}
\hline & Independent variables & & Dependent variables & Standardized estimates & t-Values & $\begin{array}{l}\text { Test of } \\
\text { hypothesis }\end{array}$ \\
\hline $\mathrm{H} 1$ & $\mathrm{AT}$ & $\rightarrow$ & LEPBI & .079 & .738 & Rejected \\
\hline $\mathrm{H} 2$ & AT & $\rightarrow$ & HEPBI & .181 & 1.690 & Rejected \\
\hline $\mathrm{H} 3$ & $\mathrm{SN}$ & $\rightarrow$ & LEPBI & .429 & $4.602 * * *$ & Supported \\
\hline $\mathrm{H} 4$ & $\mathrm{SN}$ & $\rightarrow$ & HEPBI & .181 & $2.001 *$ & Supported \\
\hline H5 & PBC & $\rightarrow$ & LEPBI & -.055 & -.407 & Rejected \\
\hline H6 & PBC & $\rightarrow$ & HEPBI & .111 & .813 & Rejected \\
\hline $\mathrm{H} 7$ & PAA & $\rightarrow$ & LEPBI & .308 & $3.341 * * *$ & Supported \\
\hline H8 & PAA & $\rightarrow$ & HEPBI & .318 & $3.434 * * *$ & Supported \\
\hline H9 & NAA & $\rightarrow$ & LEPBI & -.098 & -.823 & Rejected \\
\hline H10 & NAA & $\rightarrow$ & HEPBI & .018 & .153 & Rejected \\
\hline H11 & AT & $\rightarrow$ & PAA & .424 & $6.408 * * *$ & Supported \\
\hline H12 & $\mathrm{SN}$ & $\rightarrow$ & PAA & .143 & $2.069^{*}$ & Supported \\
\hline H13 & PBC & $\rightarrow$ & PAA & .382 & $4.428 * * *$ & Supported \\
\hline H14 & $\mathrm{AT}$ & $\rightarrow$ & NAA & .289 & $3.930 * * *$ & Supported \\
\hline H15 & $\mathrm{SN}$ & $\rightarrow$ & NAA & .266 & $3.219^{* *}$ & Supported \\
\hline H16 & PBC & $\rightarrow$ & NAA & .238 & $2.478^{*}$ & Supported \\
\hline \multicolumn{3}{|c|}{$\begin{array}{l}\text { Total variance explained }\left(\mathrm{R}^{2}\right) \\
\mathrm{R}^{2} \text { for Positive anticipated affect }=.678 \\
\mathrm{R}^{2} \text { for Negative anticipated affect }=.463 \\
\mathrm{R}^{2} \text { for Low effort pro-environmental } \\
\text { intention }=.448 \\
\mathrm{R}^{2} \text { for High effort pro-environmental } \\
\text { intention }=.208\end{array}$} & \multicolumn{3}{|c|}{$* \mathrm{p}<.05 ; * * \mathrm{p}<.01 ; * * * \mathrm{p}<.001$} & \\
\hline
\end{tabular}


Table 5. Standardized total impact and indirect impact

\begin{tabular}{|c|c|c|c|c|c|}
\hline Independent variables & & Dependent variables & Direct impact & Indirect impact & Total impact \\
\hline $\mathrm{AT}$ & $\rightarrow$ & LEPBI & .079 & $.149 * *$ & $.149 * *$ \\
\hline $\mathrm{SN}$ & $\rightarrow$ & LEPBI & $.429 * * *$ & $.045^{*}$ & $.488 *$ \\
\hline $\mathrm{PBC}$ & $\rightarrow$ & LEPBI & -.055 & $.117 * *$ & $.117 * *$ \\
\hline PAA & $\rightarrow$ & LEPBI & $.308 * * *$ & - & $.308 * * *$ \\
\hline NAA & $\rightarrow$ & LEPBI & -.098 & - & -.098 \\
\hline AT & $\rightarrow$ & HEPBI & .181 & $.177 * *$ & $.177 * *$ \\
\hline $\mathrm{SN}$ & $\rightarrow$ & HEPBI & $.181 *$ & $.054 *$ & $.269 *$ \\
\hline PBC & $\rightarrow$ & HEPBI & .111 & $.140 * *$ & $.140 * *$ \\
\hline PAA & $\rightarrow$ & HEPBI & $.318^{* * *}$ & - & $.318^{* * *}$ \\
\hline NAA & $\rightarrow$ & HEPBI & .018 & - & .018 \\
\hline
\end{tabular}


Supplementary data:

Figure 1. Conceptual model.

Figure 2. Structural results of the proposed model.

Questionnaire 